\title{
ASSESSMENT OF QUALITY OF LIFE AFTER HYSTERECTOMY WITH OPPORTUNISTIC SALPINGECTOMY WITH UTERINE MYOMA BY VAGINAL AND ABDOMINAL ACCESS
}

\section{Olha Proshchenko, Iryna Ventskivska, Yaroslav Vitovsky, Svitlana Markitanyuk}

\begin{abstract}
The aim of the research - to identify violations of quality of life after hysterectomy with opportunistic salpingectomy, considering different approaches to surgery.

Materials and methods. Quality of life assessments of hysterectomy with opportunistic salpingectomy for uterine fibroids were performed in 160 women of reproductive age, who were divided into two groups: I-90 patients with vaginal access, and II - 70 patients with abdominal access. The control group included 50 women with asymptomatic fibroids of reproductive age. The diagnostic algorithm included a physical examination, ultrasound examination of the pelvic organs, assessment of urogenital dysfunction questionnaire using the MOS SF-36 questionnaire; to identify signs of vegetative changes in Wayne, to assess general fatigue, physical and mental fatigue MFI-20 was performed using a standardized POP-Q system.
\end{abstract}

Results. The leading violations of quality-of-life parameters are general somatic symptoms 107 (66.9 $16.0 \%)$, psycho-

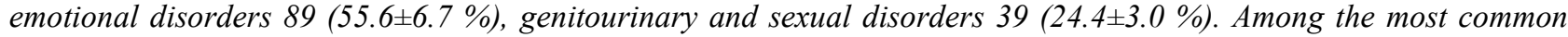
somatic ones - complaints of headaches, edema and fluctuations in blood pressure. The dominance of asthenic, anxiety and depressive disorders among psycho-emotional disorders has been established. The diagnosis of "organic asthenic

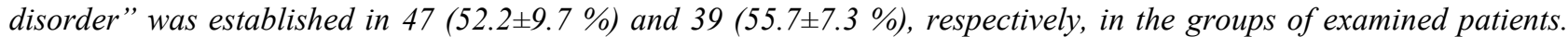
Vaginal hysterectomy causes more increase in the proportion of urogenital disorders $2527.7 \pm 8.3 \%$ compared to control $-7(14.0 \pm 4.8 \%)(p<0.05)$. An ultrasound examination showed a 2.25-fold increase in ovarian volume one month after the hysterectomy, and a reduction in ovarian tissue volume in both study groups 2 years after surgery.

Conclusions. Hysterectomy with opportunistic salpingectomy affects the parameters of quality of life. The leading violations of quality-of-life parameters are general somatic symptoms, psycho-emotional disorders without statistically significant difference in groups, but the indicators are better in group I. The minimal effect on ovarian function and size was determined - 2 years after surgery, there was a decrease in ovarian tissue volume in both study groups, but statistically significant - in the second group $\left(3.12 \pm 0.7 \mathrm{~cm}^{3}, p<0.05\right)$ against the data control $\left(5.82 \pm 1.7 \mathrm{~cm}^{3}\right)$. Although the results showed a more frequent manifestation of pelvic floor descent in vaginal access, quality of life parameters were higher in these patients. Given its safety, efficiency and cost-effectiveness, it is advisable to choose it as a method of choice

Keywords: uterine fibroids, hysterectomy, quality of life parameters, opportunistic salpingectomy

How to cite:

Proshchenko, O., Ventskivska, I., Vitovsky, Y., Markitanyuk, S. (2022). Assessment of quality of life after hysterectomy with opportunistic salpingectomy with uterine myoma by vaginal and abdominal access. ScienceRise: Medical Science, 1 (46), 25-30. doi: http://doi.org/10.15587/25194798.2022 .252941

(C) The Author(s) 2022

This is an open access article under the Creative Commons CC BY license hydrate

\section{Introduction}

Despite the significant variety of treatments for uterine fibroids at the present stage of development of gynecology, the frequency of hysterectomy remains consistently high, in Sweden $-38 \%$, in the US - $36 \%$, in the UK $-25 \%$ [1]. Most scientific sources claim that vaginal hysterectomy is the safest, most effective and cost-effective surgical method for removing the uterus. However, abdominal access is still most often chosen $56 \%$ of all hysterectomies are performed abdominal, $22 \%$ - vaginally and $22 \%$ - laparoscopically [2, 3].

However, surgical treatment, which is considered a safe and effective procedure, continues to increase the share of numerous adverse effects - from blood loss, pelvic injuries, anesthesia risks, loss of fertility to psycho-emotional disorders, vegetative-hormonal homeostasis and the risk of diseases of extragenital organs and systems. The relationship between uterine fibroid surgery and ovarian function, the patient's neuropsychological status, cardiovascular system, bladder function, and overall quality of life is widely discussed $[4,5]$. After surgery on the uterus, the prevalence of mental disorders and psychological problems is 50-90\%, sexual changes are observed in $48-50 \%$ of cases [6]. It should be noted not entirely definite and contradictory point of view on the pathogenesis of vegetative-neurotic and metabolic 
disorders in hysterectomy, when the main in the occurrence of psycho-autonomic disorders see psychological factors - inferiority, defeminization, etc. or hormonal imbalances due to as a result, decreased production of steroid hormones. At the same time, ovarian cancer has the highest mortality rate among all gynecological malignancies with a five-year survival rate of $30 \%$ to $40 \%$. Over the past two decades, it has become clear and increasingly accepted that most ovarian cancers originate in the epithelium of the fallopian tubes rather than the ovary itself. This paradigm shift has opened up new opportunities for ovarian cancer prevention. Salpingectomy during a hysterectomy for benign diseases (also known as opportunistic salpingectomy) could reduce the overall incidence of ovarian cancer. However, given the preventive nature of opportunistic salpingectomy, safety and assessment of possible adverse effects are important. The most important in the concept of safety are the risk of surgical complications and the impact on postoperative hormonal status. Therefore, in August 2019, a group of scientists from the Netherlands and the United Kingdom published a study comparing the benefits and risks of hysterectomy with opportunistic salpinectomy with hysterectomy without opportunistic salpinectomy at the Cochrane Library. There was no difference in hormonal postoperative status between groups after hysterectomy with or without opportunistic salpingectomy, but insufficient data were found to assess whether there was any difference in the occurrence of surgical complications. The maximum difference before menopause, calculated from the lower limit of $95 \% \mathrm{CI}$ and the natural mean decrease in AMG, was approximately 20 months, which was considered clinically insignificant [7].

Thus, despite the extensive practical experience of using the most common surgical gynecological intervention in recent decades - hysterectomy, there are discussions about the diversity of its volume, access [8-10]. These controversial issues should be considered not only from the standpoint of cancer prevention or reduction of complications, but also given the general health and quality of life of such patients in particular, this problem is insufficiently assessed and superficially presented in modern research.

The aim of the research - to identify the features and severity of violations of quality of life after hysterectomy with opportunistic salpingectomy, considering the different approaches to surgery.

\section{Materials and methods}

During the research in the gynecological department of the "Perinatal Center of Kyiv" retrospective analysis of 760 cases of hysterectomy for the period 2015-2019 was conducted. The next step was a comprehensive assessment of the impact on quality of life of hysterectomy with opportunistic salpingectomy for uterine fibroids in 160 women of reproductive age, who were divided into two groups: I - 90 patients aged $45.9 \pm 1.3$ years, where it was performed vaginal hysterectomy with tubes (first group), both classical and associat- ed with laparoscopy, and II - 70 patients who underwent abdominal hysterectomy with tubes (second group), mean age $47.2 \pm 1.6$ years. The control group included 50 women with asymptomatic fibroids of reproductive age $45.7 \pm 1.3$ years.

Exclusion criteria were: history of ovariectomy, malignancies of any localization, severe somatic pathology, patients' refusal to participate in the study.

The diagnostic algorithm included a description of the parameters of quality of life, both at the stage of preoperative observation and for 3 years after surgery. Assessment of quality-of-life parameters was performed by questionnaire using the MOS SF-36 questionnaire, to assess the vegetative status used Wayne's "Questionnaire to identify signs of autonomic changes" (Wayne A. M., 1998). To study the severity of asthenic syndrome asthenic scale, as well as a questionnaire to assess general fatigue, physical and mental fatigue MFI-20 (Multidimensional Fatigue Inventory). Assessment of pelvic floor condition and urogenital dysfunction using a standardized POP-Q system, cough test, Valsalva test, stop test with Kegel cones, etc. were used. All women were interviewed, completed diaries of pain, urination, physical examination, ultrasound examination of the pelvic organs.

Statistical processing of the results was performed using statistical packages IBM SPSS Statistics (ver. 21) and statistical environment R (ver. 3.1). Assessment of variability of indicators was performed by methods of variation statistics. For comparative analysis, we used the methods of nonparametric statistics - the Chi-square criterion $\left(\chi^{2}\right)$ and used Fisher's exact criterion.

All questions regarding the possibility of conducting these studies were agreed with the Commission on Bioethical Expertise and Ethics of Scientific Research of the "National Medical University named after O. O. Bogomolets" protocol No. 140 dated 21.12.2020, the study was performed with the analysis of medical records before surgical recovery in retrospect, all patients gave their voluntary consent to the examination, questionnaire. The research is based on ethical standards in accordance with the Helsinki Declaration of the World Medical Association (THE 52ND WMA GENERAL ASSEMBLY, EDINBURGH, SCOTLAND, OCTOBER 2000).

\section{Research results}

At the first stage, in connection with the set goal, a medical and social audit of 760 cases of hysterectomies for the period 2015-2019 was conducted through interviews, questionnaires and clinical and paraclinical analysis of medical records, taking into account the methods, scope of rehabilitation and operational access, as well as factors of socio-economic and psycho-emotional nature. The share of fibroids in women of reproductive age has been increased 1.7 times from $19.1 \%$ (124 patients) in 2015 to $32.9 \%$ (229 patients) in 2019 (p <0.05), where more than two thirds of the method of surgical recovery traditionally remains a hysterectomy (Fig. 1). 


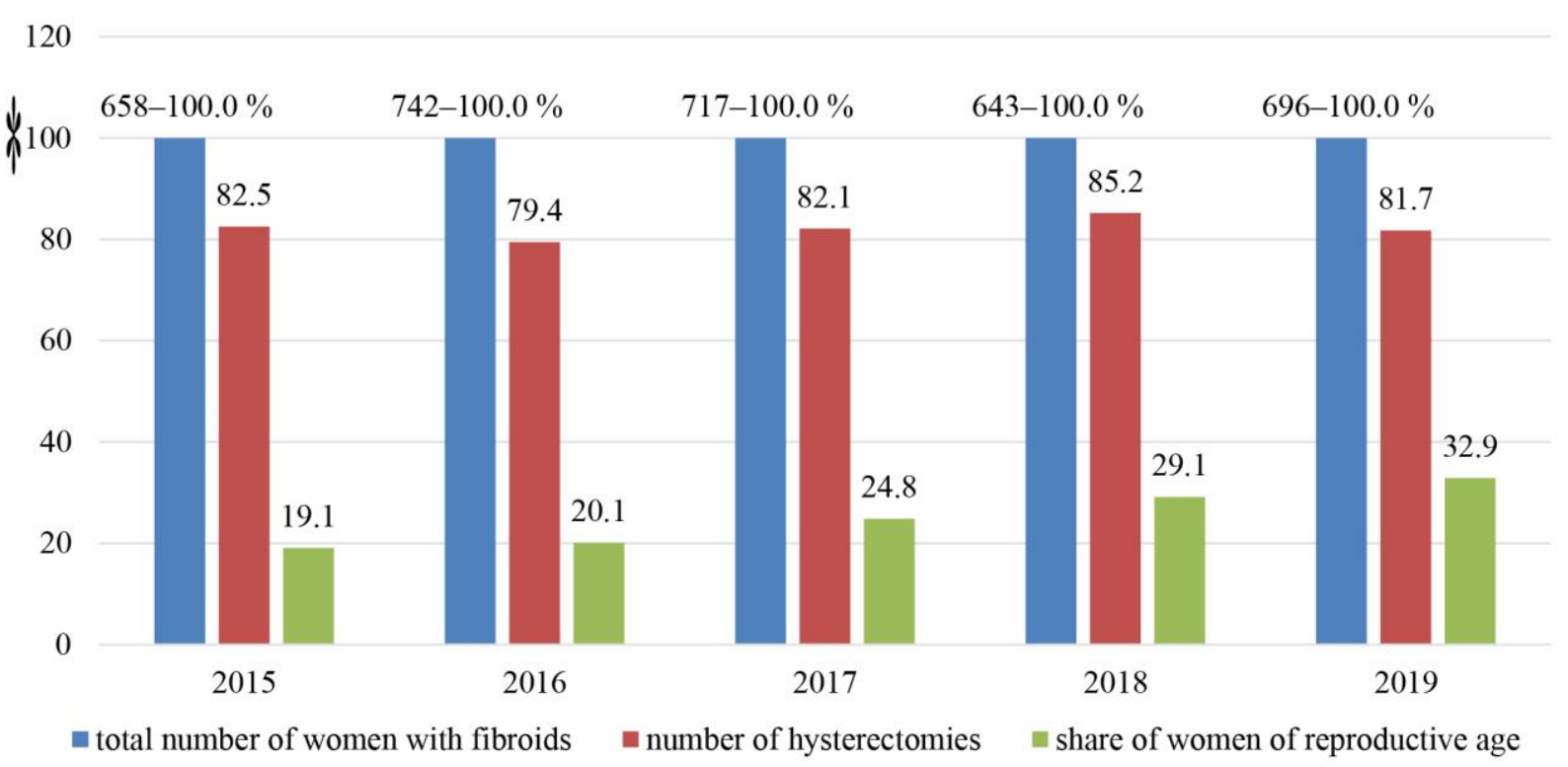

Fig. 1. The share of uterine fibroids and hysterectomy in reproductive age $\%$ : $*$ - statistically significant difference compared to 2015 data, $\mathrm{p}<0,05$

Evaluating the presented in Fig. 2 data, during analytical processing of medical documentation changes in the structure of access were noted - a tendency to decrease the frequency of abdominal hysterectomy and in- crease vaginal hysterectomy, including laparoscopically assisted (LAVH). More than half of the observations in $2015-55.0 \%$ of hysterectomies in patients of reproductive age were performed to preserve the fallopian tubes.

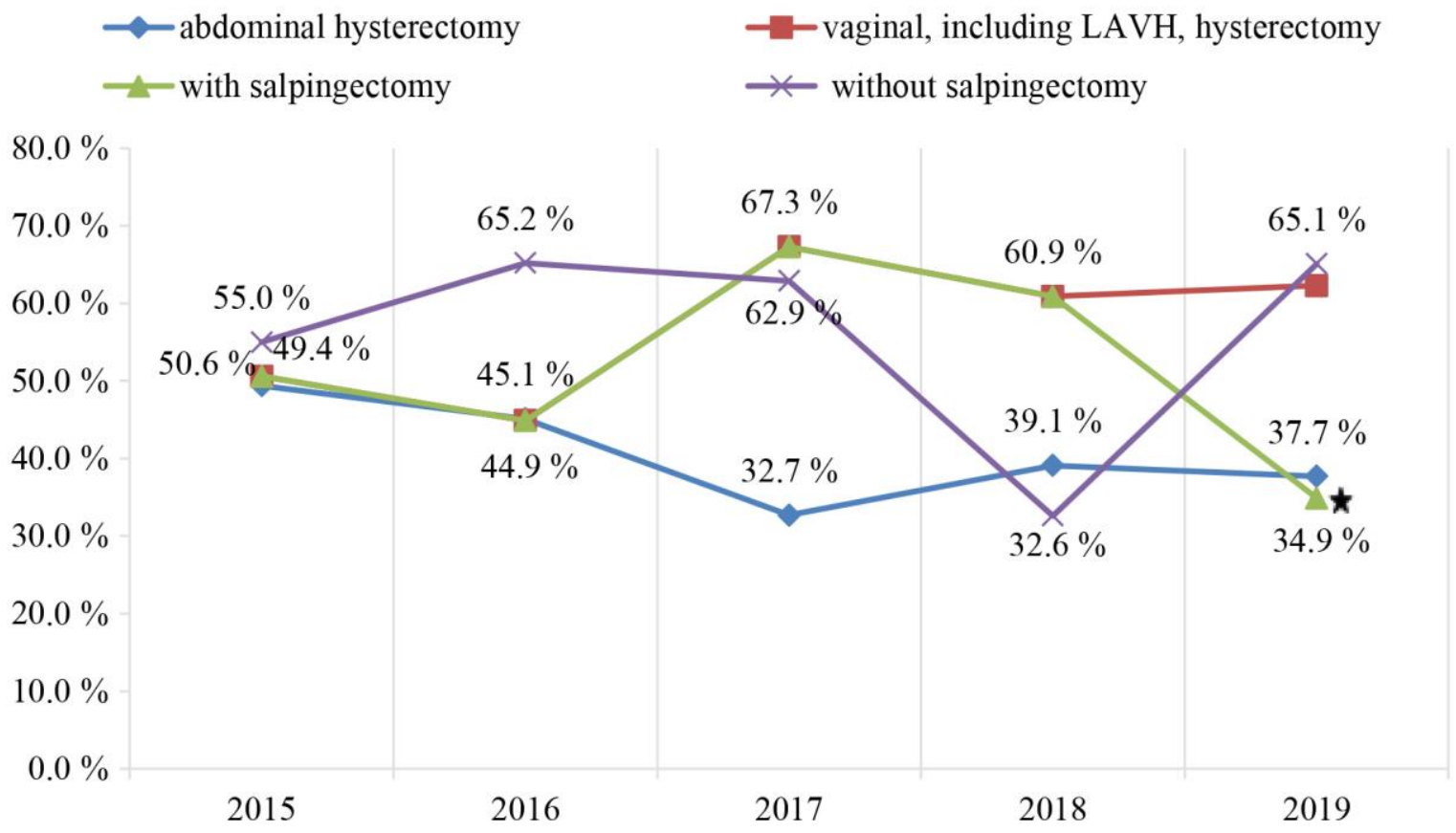

Fig. 2. Features of hysterectomy for uterine fibroids in patients of reproductive age, $\%$ : * - statistically significant difference compared to 2015 data, $\mathrm{p}<0.05$

According to the results of this study, in women of reproductive age after hysterectomy with opportunistic salpingectomy for fibroids, we found that the leading violations of quality of life are somatic symptoms 107 $(66.9 \pm 6.0 \%)$ compared with control - $13(26.0 \pm 8.7 \%)$, psycho-emotional disorders $89(55.6 \pm 6.7 \%)$ compared with control $-11(22.0 \pm 8.7 \%)$, genitourinary and sexual disorders $39(24.4 \pm 3.0 \%)$ compared with control -
$7(14.0 \pm 4.8 \%)$. It should be noted that during the firstyear psycho-emotional - fatigue, mood lability, emotional (in 49 cases $(30.6 \pm 6.4 \%)$ and vascular manifestations) were predominant in 113 people $(70.6 \pm 4.8 \%)$, while metabolic and endocrine deviations were practically not noted. Traditionally, among the somatic there were manifestations of vegetative-vascular symptom complex. The most significant were complaints of headaches - up to 
$55.6 \pm 7.0 \%$ (50 patients) in group I and $62.8 \pm 8.0 \%$ (44 patients) in group II, edema and fluctuations in blood pressure - up to $46.7 \pm 7.5 \%$ (42 patients) in group I and $61.4 \pm 8.3 \%$ (43 patients) in group II, primarily due to hypertension. At the same time, 34 patients in group I and $38.6 \pm 7.3 \%$ and 27 patients in group II noted the appearance episodes of palpitations and hot flashes - up to $37.8 \pm 6.5 \%$, and their frequency is more common in women of the second group and was statistically significantly higher than in the control group of $14.0 \pm 4.3 \%$ (7 patients), a significant proportion of respondents are concerned about paresthesias and allergic reactions $(p<0.05)$. It should be noted an increase in the proportion of mild and moderate symptoms of menopausal syndrome in women of the second group up to 36 months postoperatively. And only in 6 patients of the first group $(6.7 \%)$ there were pronounced manifestations, which were regarded as hot flashes, in the first 6 months after surgery, which up to three years were observed in isolated cases, while in patients of the second group indications of severe hot flashes in the questionnaires were noted 1.7 times more often $(12.9 \pm 2.3 \%-$ 9 patients).

Ultrasound examination one month after hysterectomy revealed an increase in ovarian volume of approximately 2.25 -fold, along with a decrease in ovarian artery blood flow (Fig. 3) and a decrease in ovarian echogenicity. Characterizing the sonographic features of ovarian tissue 2 years after surgery, there was a decrease in ovarian tissue in both study groups, but statistically significant - in the second group $\left(3.12 \pm 0.7 \mathrm{~cm}^{3}, \mathrm{p}<0.05\right)$ against the control data $\left(5.82 \pm 1.7 \mathrm{~cm}^{3}\right)$.
Right ovary volume

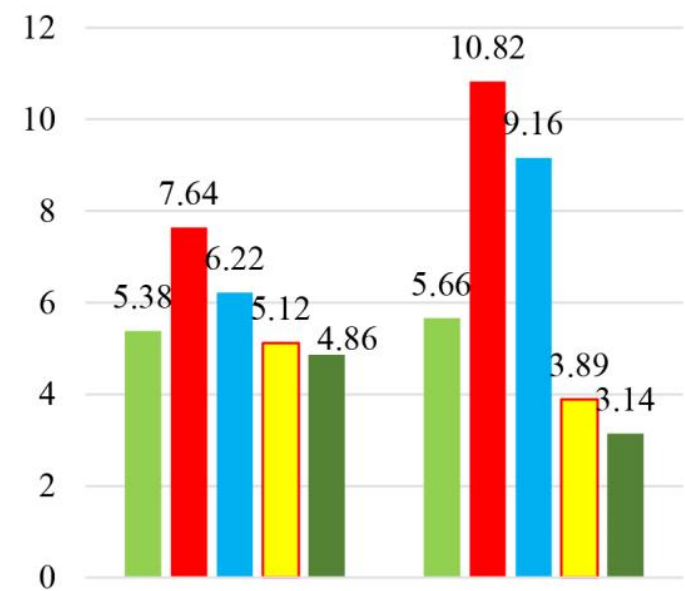

First group, $n=90$ Second group, $n=70$
Left ovary volume

12

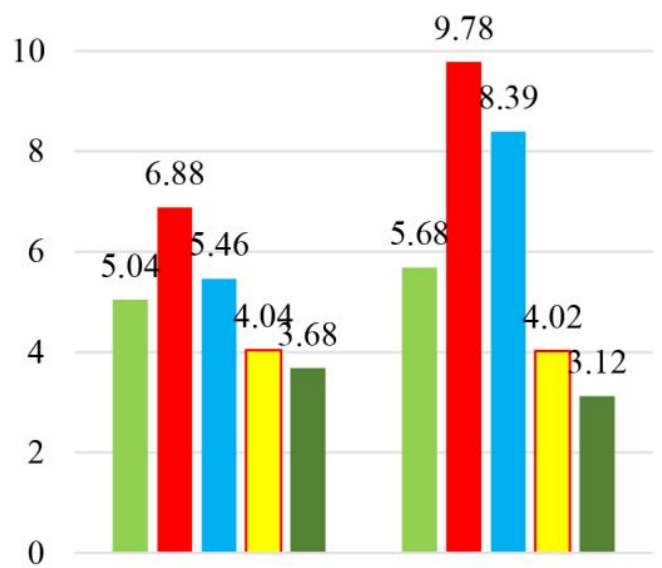

First group, $n=90$ Second group, $n=70$

Before the operation

- Early postoperative period

" 6 months after surgery

$\square 12$ months after surgery

- 24 months after surgery

Fig. 3. Dynamics of changes in ovarian tissue volume during postoperative monitoring, $\mathrm{cm}^{3}$.

The results of the survey indicate anxiety in 102 patients $(63.8 \pm 12.7 \%)$, reduced efficiency of 86 patients $(53.6 \pm 9.7 \%)$, mental anxiety and dyssomnia in 44 patients $(27.5 \pm 9.7 \%)$. According to the questionnaire using the Asthenic Scale and the MFI-20 General, Physical and Mental Fatigue Assessment Questionnaire, the diagnosis of "organic asthenic disorder" was found in
$47(52.2 \pm 9.7 \%)$ and $39(55.7 \pm 7.3 \%)$, respectively, by groups of examined patients. Regarding genitourinary disorders - signs of stress urinary incontinence and imperative forms of urinary incontinence with statistically significant deviations in the case of vaginal hysterectomy - in 25 cases $(27.7 \pm 8.3 \% \mathrm{p}<0.05)$ and $12-(17.1 \pm 7.8 \%)$, compared with the control $-7(14.0 \pm 4.8 \%)$. 


\section{Discussion}

According to the results of the analysis of medical documentation 760 cases of hysterectomies for the period 2015-2019 The structure of the incidence of uterine fibroids is as follows: the incidence of uterine fibroids remains a pressing issue for practical gynecology without a tendency to reduce its share in the structure of gynecological morbidity, and hysterectomy is the treatment of choice in more than two-thirds of patients (from $79 \%$ to $82 \%$ ), which coincides with the literature [1]. Moreover, its frequency is high in women of reproductive age $-32.9 \%$ (229 people) - in 2019 with a tendency to increase. The demonstrated high percentage of hysterectomy is apparently due to hospitalization of predominantly symptomatic fibroids resistant to conservative treatment options.

In half of the observations in 2015 - hysterectomy in $55.0 \%$ of patients of reproductive age was performed with preservation of the fallopian tubes, which is apparently due to the existing literature on the deterioration of ovarian blood supply and a brighter clinic of posthysterectomy syndrome in the case of salpingoectomy [4, 5]. At the same time, other studies show minimal impact on hormone-producing function of the ovaries, and the expected benefits in reducing the risk of ovarian cancer, justifies its feasibility [1]. This analysis was the impetus for our study. At the same time, there are changes in the structure of access - a tendency to reduce the frequency of abdominal hysterectomy and increase vaginal hysterectomy, including laparoscopically assisted.

According to the results of the study of quality-oflife parameters, it was determined that the leading disorders are general somatic symptoms 107 (66.9 $\pm 6.0 \%)$. Traditionally, among them were manifestations of vegetative-vascular symptom complex - headaches, edema and fluctuations in blood pressure and more severe in patients of the second group. The nature of autonomic dysregulation of the cardiovascular system was manifested by tachycardia, decreased values of shock and cardiac indices, increased vascular resistance in the periphery and increased blood pressure. This indicates the possible activation of pathogenetic mechanisms of circulatory disorders after abdominal surgery, along with a decrease in estradiol levels, the formation of chronic stress, which is a prerequisite for the development of hypertension. At the same time, one in three patients had episodes of palpitations and hot flashes - up to $37.8 \pm 6.5 \%(\mathrm{p}<0.05)$ (34 patients) in group I and 38.6 $\pm 7.3 \%(p<0.05)$ (27 patients) in group II, and their frequency is more common in women of the second group.

An ultrasound examination one month after the hysterectomy revealed an increase in ovarian volume of approximately 2.25 , and 2 years later a decrease in ovarian tissue volume was found in both study groups. It is known that there are three types of ovarian blood supply, in $51 \%$ of cases the ovary is evenly supplied from the uterine and ovarian arteries, in $38 \%$ - mainly due to the uterine artery, in $11 \%$ - mainly due to the ovarian artery. Thus, it is obvious that the magnitude of the impact of the intersection during the operation of the ovarianfallopian tube on the completeness of the blood supply to the gonads will depend on the type of blood supply. In addition, the absence of valves in the ovarian veins contributes to the development of their varicose veins, which means a slowdown in venous blood flow due to loss of uterine-ovarian anastomosis after hysterectomy.

In the analysis of the questionnaire, patients most often indicate such disorders of psycho-emotional status as anxiety of 102 patients $(63.8 \pm 12.7 \%)$, reduced efficiency of 86 patients $(53.6 \pm 9.7 \%)$. Symptoms of psychological status imbalance were most pronounced in older patients and in the case of abdominal access. Almost half were diagnosed with "organic asthenic disorder". Most noted the first signs of psychoemotional and vegetative-vascular disorders in the first year after surgery, dominated by complaints such as general fatigue, decreased physical activity, anxiety, increased emotionality, episodes of depressive symptoms, and chronic pelvic pain syndrome. Over time, in the remote postoperative period, the manifestations of psychoemotional maladaptation progressively decrease, so after three years the first complaints were noted by a small proportion of respondents $-31(19.4 \pm 7.3 \%)$.

Psycho-emotional disorders after hysterectomy are caused, including increasing genitourinary manifestations. The obtained results showed the manifestation of pelvic floor descent in almost every third patient, with statistically significant deviations in the case of vaginal hysterectomy. This could be explained by the fact that the conditions for performing a vaginal hysterectomy in addition to the mobility and size of the uterus is also sufficient vaginal capacity, and therefore these women may have predictors of vaginal prolapse or pre-existing minimal asymptomatic lowering of the vaginal walls. On the other hand, estrogen deficiency is a risk factor for genital prolapse and urinary incontinence. Given the reduced functional activity of the ovaries and the development of atrophic processes in estrogen-dependent tissues, urinary incontinence should not be considered as a consequence of damage and incoordination of anatomical structures of the pelvis and pelvic floor due to surgery, but also to take into account, which causes the risk of genitourinary disorders, and in reproductive age initiates related psycho-emotional disorders. With increasing duration of the postoperative period, estrogen-dependent atrophic process progresses, which is manifested by increased urogenital manifestations with increasing proportion of stress and urinary incontinence.

Study limitations. The results of the analysis reflect the data only of the gynecological department of the "Kyiv Perinatal Center". Because not all patients joined the study after hysterectomy, there may be shifts in the results of the study due to underrepresentation. However, the study has representative and comparable groups.

Prospects for further research. Thus, existing research does not pay enough attention to the impact of opportunistic hysterectomy on uterine fibroids in the complex on the problem of hormonal disorders of homeostasis, genitourinary syndrome, the formation of psychovegetative symptom complex, and as a consequence, changes in quality of life, as a component of an optimized rehabilitation program with personalized consideration of the leading factors of status comorbidity when planning surgical treatment, meeting all the criteria for selecting patients for its use and depending on the somatic health index. Another important area is the development and improvement of measures for the prevention of posthysterectomy genitourinary syndrome. 


\section{Conclusions}

A retrospective study found that more than half of the observations in 2015 - 55.0\% hysterectomy in patients of reproductive age was performed to preserve the fallopian tubes, which was apparently due to existing literature on the deterioration of ovarian blood supply.

Hysterectomy with opportunistic salpingectomy, performed in reproductive age causes a decrease in quality of life and may contribute to the development of imbalance of hormonal homeostasis, psycho-emotional, vegetative-neurotic symptoms, initiating or exacerbating sexual and urogenital dysfunction. The leading violations of quality of life parameters are general somatic symptoms $107(66.9 \pm 6.0 \%)$, psycho-emotional disorders 89 $(55.6 \pm 6.7 \%)$, without a statistically significant difference by groups, but the indicators are better in group I. The dominance of asthenic, anxiety and depressive disorders among psycho-emotional disorders has been established. The diagnosis of "organic asthenic disorder" was established in $47(52.2 \pm 9.7 \%)$ and 39 (55.7 $7.3 \%)$, respectively, in the groups of examined patients - without significant difference. Genitourinary and sexual disorders $39(24.4 \pm 3.0 \%)$ were identified, which could be initiated by estrogenic deficiency and aggravate psycho- emotional disorders. The results showed a more frequent manifestation of pelvic floor descent $(25-27.7 \pm 8.3 \%)$ compared to the control $-7(14.0 \pm 4.8 \%)$ with vaginal access $(\mathrm{p}<0.05)$.

Opportunistic salpingectomy with hysterectomy has minimal effect on ovarian function and size -2 years after surgery, there was a decrease in ovarian tissue in both groups, but statistically significant - in the second group $\left(3.12 \pm 0.7 \mathrm{~cm}^{3}, \mathrm{p}<0.05\right)$ against the control data $\left(5.82 \pm 1.7 \mathrm{~cm}^{3}\right)$. Therefore, the expected benefit in reducing the risk of ovarian cancer provides the feasibility of its implementation.

\section{Conflict of interests}

The authors declare that they have no conflicts of interest.

\section{Funding}

The study was performed at its own expense within the scientific program of the Department of Obstetrics and Gynecology No. 1 "Bogomolets National Medical University": "Preservation and restoration of women's reproductive health, taking into account medical and social consequences", 0119 U103879.

\section{References}

1. Fernandez, H., Farrugia, M., Jones, S. E., Mauskopf, J. A., Oppelt, P., Subramanian, D. (2009). Rate, Type, and Cost of Invasive Interventions for Uterine Myomas in Germany, France, and England. Journal of Minimally Invasive Gynecology, 16 (1), $40-46$. doi: http://doi.org/10.1016/j.jmig.2008.09.581

2. Zabolotnov, V. A., Karapetian, O. V., Pamfamirov, Iu. K., Pamfamirova, G. L., Kucherenko, Iu. A., Tatevosian, A. G. (2011). Sovremennye vzgliady na etiologiiu, patogenez i lechenie miomy matki. Zdorove zhenschiny, 5 (61), 15-20.

3. Stewart, E. A., Shuster, L. T., Rocca, W. A. (2012). Reassessing Hysterectomy. Minnesota Medicine, 95 (3), 36-39.

4. Lashkul, O. S. (2018). Quality of life and sexual function of women operated on reproductive system organs. Zaporozhye Medical Journal, 20 (1 (106)), 7681. doi: http://doi.org/10.14739/2310-1210.2018.1.121999

5. Vomvolaki, E., Kalmantis, K., Kioses, E., Antsaklis, A. (2006). The effect of hysterectomy on sexuality and psychological changes. The European Journal of Contraception \& Reproductive Health Care, 11 (1), 23-27. doi: http://doi.org/10.1080/13625180500430200

6. Roseske, N. C. (2007). Hysterectomy and other gynecological surgeries: a psychological view. Women's place in medical and psychological interfaces, 1, 172-180.

7. Van Lieshout, L. A. M., Steenbeek, M. P., De Hullu, J. A., Vos, M. C., Houterman, S., Wilkinson, J., Piek, J. M. (2019). Hysterectomy with opportunistic salpingectomy versus hysterectomy alone. Cochrane Database of Systematic Reviews, 8. doi: http://doi.org/10.1002/14651858.cd012858.pub2

8. Evstifeeva, E. A., Filippchenkova, S. I., Kalantarov, T. K., Kholodin, S. P. (2016). Psikhosomaticheskaia sostavliaiuschaia i kachestvo zhizni bolnykh khirurgicheskogo profilia. Arkhiv vnutrennei meditsiny. Spetsialnyi vypusk, 61.

9. Zagorodniaia, E. D., Barkan, T. M., Kolecnikov, A. D., Barkan, V. C., Rezanovich, V. C., Butunov, A. A., Tseliuba, E. A. (2013). Vliianie gicterektomii na funktsiiu iaichnikov i kachectvo zhizni bolnykh miomoi matki. Akusherctvo i ginekologiia, 2, $48-81$.

10. Savvina, N. V., Savvina, A. D. et. al. (2013). Kachestvo zhizni kak pokazatel effektivnosti reabilitatsionnykh meropriiatii. Vestnik natsionalnogo mediko-khirurgicheskogo tsentra im. N. I. Pirogova, 3 (8), 41-43.

Received date 02.11.2021

Accepted date 14.12.2021

Published date 30.01.2022

Olha Proshchenko*, PhD, Assistant, Department of Obstetrics and Gynecology No. 1, Bogomolets National Medical University, T. Shevchenko blvd., 13, Kyiv, Ukraine, 01601

Iryna Ventskivska, Doctor of Medical Sciences, Head of Department, Department of Obstetrics and Gynecology No. 1, Bogomolets National Medical University, T. Shevchenko blvd., 13, Kyiv, Ukraine, 01601

Yaroslav Vitovsky, PhD, Associate Professor, Department of Obstetrics and Gynecology No. 1, Bogomolets National Medical University, T. Shevchenko blvd., 13, Kyiv, Ukraine, 01601

Svitlana Markitanyuk, PhD, Obstetrician-Gynecologist, Kyiv Perinatal Center, Predslavinska str., 9, Kyiv, Ukraine, 03150 